\title{
LA EXPROPIACIÓN PÚBLICA EN BAJA CALIFORNIA, UNA VIOLACIÓN AL DERECHO FUNDAMENTAL DE LA PROPIEDAD PRIVADA EN MÉXICO
}

\section{PUBLIC EXPROPRIATION IN BAJA CALIFORNIA, A VIOLATION OF THE FUNDAMENTAL RIGHT OF PRIVATE PROPERTY IN MEXICO}

\author{
Alejandro Sánchez Sánchez ${ }^{1}$ \\ Luis Carlos Castro Vizcarra ${ }^{2}$ \\ Luis Enrique Concepción Montiel ${ }^{3}$
}

\section{Resumen}

La propiedad privada en México, la constituye el Estado mexicano en el ejercicio soberano de otorgar el dominio de las tierras y aguas, es un derecho fundamental, sin embargo, la nación tiene la obligación de expropiar por causa de utilidad pública, esto se replica en las entidades federativas, pero tanto la federación como los estados, para desposeer, deben cumplir con los principios constitucionales y legales, pues en el caso contrario, el propietario goza de los mecanismos de control constitucional, como lo es el juicio de amparo, inclusive la reversión del bien expropiado. El objetivo planteado fue analizar la norma jurídica que regula la expropiación; lo que se efectuó utilizando un método cualitativo, con un alcance descriptivo, correlacional, explicativo y analítico deductivo; resultando que la propiedad privada en México es un derecho fundamental, sobre el cual el Estado puede expropiar sujetándose a los principios establecidos, para lo cual el gobernado goza de las garantías constitucionales; considerando que se debe actualizar la indemnización al tiempo del pago.

Palabras clave: Derecho Humano, Expropiación, Mecanismo de Control Constitucional.

\begin{abstract}
Private property in Mexico, is the Mexican State in the sovereign exercise of granting ownership of lands and waters, is a fundamental right, however, the nation has the obligation to expropriate for public utility, this is replica in the states, but both the federation and the states, to dispossess, must comply with the constitutional and legal principles, because otherwise, the owner enjoys the mechanisms of constitutional control, as is the amparo trial, including the reversion of the property expropriated. The objective was to analyze the legal norm that regulates expropriation; what was done using a qualitative method, with a descriptive, correlational, explanatory and analytical deductive scope; resulting that private property in Mexico is a fundamental right, over which the State can expropriate subject to the established

\footnotetext{
${ }^{1}$ Doctor en Derecho, Miembro del Sistema Nacional de Investigadores Nivel I, profesor investigador, catedrático a nivel licenciatura y posgrado. E-mail: alexsasacc@uabc.edu.mx

2 Doctor en Ciencias Jurídicas, perfil Promep, exbecario CONACYT, catedrático a nivel licenciatura y posgrado, autor de artículos, participación en congresos nacionales e internacional. E-mail: luiscarloscastro@uabc.edu.mx

${ }^{3}$ Doctor en Ciencias Politicas, Perfil Promep, miembro del Sitema Nacional de Investigadores NIvel I, autor de libros, articulos, participación en congresos nacionales e internacionales, profesor investigador, catedrático a nivel icenciatura y posgrado. E-mail: enriquepolitik@uabc.edu.mx
} 
principles, for which the governed enjoys the constitutional guarantees; whereas the compensation must be updated at the time of payment.

Keywords: Human Right, Expropriation, Constitutional Control Mechanism.

\section{INTRODUCCIÓN}

La expropiación pública en Baja California, es una violación al derecho fundamental de la propiedad privada, cuando el Estado expropiante no cumple con los principios constitucionales y legales que rigen esa figura jurídica, así, en los Estados Unidos Mexicanos (EUM), tanto la Federación como las entidades federativas que la integran, tienen la facultad soberana de expropiar la propiedad privada, pero deben cumplir con todos los principios constitucionales y legales de esa figura jurídica.

La propiedad privada en México, es un derecho fundamental, al estar consagrada en los artículos cuatro, catorce y el veintisiete de la parte dogmática de la Constitución Política de los Estados Unidos Mexicanos (CPEUM), su fuente es la Nación, todo corresponde o ese es su origen, a ésta, a través de sus órganos de representación pública, le corresponde el derecho de trasmitir el dominio de ella a los particulares, naciendo así la propiedad privada, ésta es el derecho real para usar, gozar y disponer de las cosas, dentro de un sistema jurídico positivo vigente; se afirma, que la propiedad privada en México es un derecho humano reconocido.

Considerando que la expropiación pública en México, después del ejercicio soberano de otorgar el dominio de las tierras y aguas a los particulares; la nación tiene la obligación de expropiar por causa de utilidad pública, esto se replica en las entidades federativas, pero tanto la federación como los estados, para desposeer, deben indemnizar y cumplir con los principios constitucionales y legales; además, si el Estado expropiante incumple con la causa de utilidad pública, es decir, no construye, ni lotifica, deja de cumplir el objeto de realización para la satisfacción de la causa de la necesidad pública, entonces el propietario originario cuenta con el recurso de reversión, para que vuelva el bien a su patrimonio.

La expropiación pública en el Estado de Baja California, México, se rige por su Ley, la cual establece que: la propiedad privada en el Estado podrá ser expropiada, por causa de utilidad pública y mediante indemnización; siendo objeto de expropiación los bienes muebles o inmuebles ${ }^{4}$, para aquel y todas las entidades federativas de los EUM, son aplicables los principios, derechos fundamentales y garantías constitucionales que se observaron en esta

\footnotetext{
${ }^{4}$ Ley de Expropiación para el Estado de Baja California, publicada en el Periódico Oficial no. 28, de fecha 13 de junio del 2003, tomo CX.
} 
investigación. Siendo el objeto de estudio la norma jurídica, se afirma que las tierras y aguas pertenecen originariamente al concepto de nación, ésta tiene la facultad soberana de instituir la propiedad privada, por tanto, si la expropiación en esa entidad federativa se realiza contradiciendo alguno de los principios constitucionales, constituye una violación a ese derecho fundamental en caso contrario, si se cumple y se respeta con todo el sistema jurídico que rige a la expropiación, se está ante una facultad soberana que no viola derechos fundamentales.

El mecanismo de control constitucional ante la violación al derecho humano de la propiedad privada en México, en estricto sensu ${ }^{5}$, es el juicio de amparo agotando todos sus principios $^{6}$, además, se consideran como garantías, la seguridad jurídica, el derecho de audiencia, el debido proceso, la causa de utilidad pública, la indemnización, el recurso de revocación, el juicio de nulidad y el recurso de reversión, por lo que se razona que en México, se viola el derecho fundamental a la propiedad privada, pero el gobernado goza de todo un sistema jurídico de protección con el cual puede revertir el acto de autoridad arbitrario.

\section{LA PROPIEDAD PRIVADA EN MÉXICO, ¿DERECHO FUNDAMENTAL O NO?}

En los EUM, la tierra y el agua corresponden originariamente a la Nación, es decir, que de conformidad con el derecho internacional el territorio y el agua es de México o del País, a éste le corresponde el derecho de trasmitir el dominio de ellas a los particulares, así lo establece la parte dogmática de la CPEUM en los términos siguientes: La propiedad de las tierras y aguas comprendidas dentro de los límites del territorio nacional, corresponde originariamente a la Nación, la cual ha tenido y tiene el derecho de transmitir el dominio de ellas

\footnotetext{
${ }^{5}$ Stricto sensu (o sensu stricto) es una expresión latina que significa «en sentido estricto» o «en sentido restringido». Suele ser muy usada en Derecho y se opone a la expresión lato sensu (o sensu lato -s. I.o sensu amplo -s. a. o s. ampl.-). Se emplea cuando para una palabra, nombre o expresión son posibles dos interpretaciones y una de ellas abarca a la otra, para indicar que el término que acompaña debe interpretarse en el más estrecho o limitado de sus significados, no en el que abarca más. https://es.wikipedia.org/wiki/Stricto_sensu, consultada el 6 de junio de 2018.

${ }^{6}$ Los principios que rigen al juicio de amparo son: El principio de instancia de parte agraviada, el de agravio personal y directo, el de estricto derecho, el de relatividad de las sentencias. Éstos no se explican por no ser objeto de estudio ni tener relación directa con la investigación, el siguiente, el principio de definitividad del acto reclamado, consiste en que antes de acudir al juicio de amparo hay que agotar todos los recursos ordinarios por los cuales pueda ser modificado el acto de autoridad, aquí se encuentra una relación o vínculo directo con el acto de expropiación, pues también, se debe observar ese principio de definitividad.
} 
a los particulares, constituyendo la propiedad privada ${ }^{7}$. Así, de esta forma, se busca explicar el origen de la propiedad de la tierra y el agua en México. Haciendo énfasis en ello, la fuente de la propiedad es el Estado, todo corresponde o es de su origen, a éste, a través de sus órganos de representación pública, le corresponde el derecho de trasmitir el dominio de ellas a los particulares, naciendo así, de origen fundamental, la propiedad privada en México.

Dejando claro, que el origen de la propiedad de la tierra y el agua en los EUM, es del país y además corresponde la trasmisión de su dominio a la Nación, de lo que resulta fundamental buscar dar respuesta a las interrogantes siguientes: ¿Qué es la propiedad privada en México? ¿Qué es un derecho fundamental? ¿La propiedad privada en México es o no un derecho?

Luis Gerardo, indica que este tópico se debe abordar analizando, en primer término, la naturaleza jurídica del acto administrativo expropiatorio y de sus consecuencias, a la luz de tres aspectos diferentes, a saber: (i) su concepto doctrinal, (ii) los fundamentos jurídicos del acto expropiatorio per se y de sus consecuencias y (iii) las principales resoluciones de los tribunales al respecto. (GONZÁLEZ, 2015)

Lo anterior, se analiza al abordar los tópicos de la propiedad privada, que es un derecho fundamental, y si la propiedad privada es o no un derecho fundamental, estas tres variables se relacionan con el acto administrativo de expropiación.

\section{¿Qué es la propiedad privada en México?}

Parafraseando, se considera que para determinar la naturaleza jurídica de la expropiación, en primer término, es necesario abundar en relación al concepto de propiedad, el autor afirma que es una pieza fundamental en el orden jurídico mexicano, de la cual se debe rastrear su origen a efecto de determinar la manera en que los hechos y actos jurídicos inciden sobre ella, sostiene, como lo es, que la propiedad privada tiene su fundamento en el artículo 27 de la CPEUM y que este establece dos tipos de propiedades: (i) la propiedad originaria y (ii) la propiedad privada. (GONZÁLEZ, 2015)

Sostiene respecto a la propiedad originaria que es también conocida como dominio eminente lo que no puede entenderse como la propiedad del Estado, sino como la potestad del

\footnotetext{
${ }^{7}$ Constitución Política de los Estados Unidos Mexicanos, publicada el 5 de febrero de 1917, a la cual se le realizó su última reforma el día 15 de septiembre de 1917, premisa fundamental establecida en el primer párrafo del artículo 27.
} 
mismo, en su carácter de imperio o de autoridad, para ejercer la función ejecutiva de expropiación sobre la propiedad privada, concluye que la propiedad originaria implica la facultad expropiatoria que el Estado, en su carácter de autoridad, puede ejercer para colmar el interés público. En consecuencia, la propiedad originaria no guarda relación con la posibilidad de que el Estado sea titular de derechos de propiedad respecto de ciertos bienes, puesto que la misma descansa en lo que la doctrina ha desarrollado como dominio directo. (GONZÁLEZ, 2015)

Respecto a la propiedad privada se afirma que el Estado puede transmitir el dominio de las tierras a los particulares, constituyéndose y reconociéndose de esa manera la propiedad privada por lo que esta adquiere una función social, por lo que no se puede entender a la propiedad privada sino es atendiendo a una función social, concluye citando a Gutiérrez y González, la propiedad privada es el derecho real más amplio para usar, gozar y disponer de las cosas, dentro del sistema jurídico positivo de limitaciones y modalidades impuestas por el legislador de cada época. (GONZÁLEZ, 2015)

Por lo que se sostiene, que la propiedad privada es un derecho fundamental del cual el propietario tiene el uso, goce, disposición y disfrute del mismo, sin que pueda ser molestado en su ejercicio por ningún tercero, incluyendo al Estado.

\section{¿Qué es un derecho fundamental?}

Un derecho fundamental se origina de un derecho humano, éstos son los inherentes al ser humano, aquellos que nos corresponden por el hecho de haber nacido como tales, que son universales, inalienables, imprescriptibles, progresivos, entonces los derechos fundamentales son aquellos derechos humanos reconocidos y positividades en la ley suprema de una nación, para el caso de los EUM, son derechos fundamentales aquellos derechos humanos reconocidos y establecidos en la CPEUM.

En la CPEUM, en su parte dogmática se encuentran reconocidos los derechos humanos, constituyendo los derechos fundamentales que se encuentran en los primeros 29 artículos, también los establecidos en la fracción cuarta del artículo $31^{8}$ relativo a los tributos, así mismo,

\footnotetext{
${ }^{8}$ Es una obligación de los mexicanos y extranjeros con inversiones en el país, contribuir para los gastos públicos, pero la doctrina y la jurisprudencia consideran como derechos fundamentales que protegen al contribuyente el hecho de que el cobro de los impuestos debe ser proporcional y equitativo a la riqueza de las personas.
} 
los consagrados en el artículo $123^{9}$ relacionados con los trabajadores, de igual forma, reconoce como derechos humanos todos aquellos establecidos en los tratados internacionales en materia de derechos humanos de los que el Estado mexicano forme parte.

Ahora bien, la CPEUM en su parte dogmática en el artículo 27 primer párrafo establece que la propiedad de las tierras y aguas comprendidas dentro de los límites del territorio nacional, corresponde originariamente a la Nación, la cual ha tenido y tiene el derecho de transmitir el dominio de ellas a los particulares, naciendo así la propiedad privada; concatenado con lo establecido en el artículo 14 del mismo ordenamiento supremo el cual fundamenta que ninguna persona puede ser privado de sus propiedades, de igual forma, el artículo 4 párrafo séptimo establece que se tiene el derecho a una vivienda digna; de las tres premisas anteriores, con un análisis sistemático e integral, se deduce que la propiedad privada es un derecho humano en los EUM.

\section{¿La propiedad privada en México es o no un derecho humano?}

De lo anterior, podemos afirmar que la propiedad privada en México es un derecho humano reconocido por la CPEUM, por lo que se constituye en un derecho fundamental que goza de las garantías constitucionales, como la seguridad jurídica, el de audiencia, el debido proceso, la causa de utilidad pública, la indemnización, el recurso de revocación, el juicio de nulidad, el juicio de amparo y el recurso de reversión, (información reiterada por tercera vez, lo que fortalece el silogismo afirmado). Al respecto, los Tribunales Colegiados de Circuito de la SCJN, sostienen que:

Expropiación. Los particulares no están legitimados para exigir la apertura del procedimiento relativo contra sus bienes, cuando estimen que éstos han sido objeto de alguna perturbación u ocupación estatal injustificada. El artículo 27, párrafo segundo, de la Constitución Política de los Estados Unidos Mexicanos establece que las expropiaciones sólo podrán decretarse por causa de utilidad pública y mediante indemnización. Este precepto contiene tanto garantías de protección del derecho humano de propiedad como una facultad soberana del Estado. En el primer aspecto, la norma establece límites para la autoridad, pues le impide apropiarse de los bienes de particulares, salvo que lo exija la utilidad pública y mediante una justa retribución. Correlativamente, dicho numeral contiene una facultad de soberanía nacional, en cuya virtud la administración pública

\footnotetext{
${ }^{9}$ Establece que toda persona tiene derecho a un trabajo digno y socialmente útil, asimismo, fundamenta la regulación entre los obreros, jornaleros, empleados domésticos, artesanos y todo contrato de trabajo, lo que se considera por la doctrina, la jurisprudencia y la Constitución misma, un derecho fundamental de las personas.
} 
puede privar al gobernado de un bien, discrecional y unilateralmente, siempre que satisfaga las garantías mencionadas. En este contexto, el precepto citado no legitima a los particulares para exigir la apertura del procedimiento de expropiación de sus bienes, cuando estimen que éstos han sido objeto de alguna perturbación u ocupación estatal injustificadas, pues sólo les permite combatir la expropiación que estimen contraria a las garantías de utilidad pública y justa indemnización, o bien, oponerse a la usurpación estatal de bienes no expropiados. En congruencia con lo anterior, los artículos 10. a 50., 70., 80. y 11 de la Ley de Expropiación tampoco facultan al propietario para solicitar la apertura de un procedimiento expropiatorio en su contra, sino que sólo admiten su intervención una vez que éste ha iniciado, a fin de escucharlo previamente a que se decrete el acto de privación (tratándose de las causas de utilidad pública previstas en las fracciones I a IV, VII, VIII, IX, XI y XII del artículo 10. de la mencionada ley). De ahí que el procedimiento expropiatorio únicamente pueda instruirse por la voluntad imperativa del Estado, y no con base en la voluntad del propietario que, por cualquier motivo, pretenda la enajenación pública de sus bienes. ${ }^{10}$

Las causas, lo que justifica, lo que autoriza al Estado para privar de la propiedad a un particular, sea persona física o moral, las establece la Ley de Expropiación, publicada en el Diario Oficial de la Federación el 25 de noviembre de 1936, la cual ha sido actualizada o reformada en dos ocasiones, el 30 de diciembre de 1949 y el cinco de junio del año 2009, quedando los supuestos hipotéticos en los términos siguientes:

Se consideran causas de utilidad pública: I.- El establecimiento, explotación o conservación de un servicio público; II.- La apertura, ampliación o alineamiento de calles, la construcción de calzadas, puentes, caminos y túneles para facilitar el tránsito urbano y suburbano; III.- El embellecimiento, ampliación y saneamiento de las poblaciones y puertos, la construcción de hospitales, escuelas, parques, jardines, campos deportivos o de aterrizaje, construcciones de oficinas para el Gobierno Federal y de cualquier obra destinada a prestar servicios de beneficio colectivo. III Bis. La construcción de obras de infraestructura pública y la prestación de servicios públicos, que requieran de bienes inmuebles y sus mejoras, derivada de concesión, de contrato o de cualquier acto jurídico celebrado en términos de las disposiciones legales aplicables. IV.- La conservación de los lugares de belleza panorámica, de las antigüedades y objetos de arte, de los edificios y monumentos arqueológicos o históricos, y de las cosas que se consideran como características notables de nuestra cultura nacional; V.- La satisfacción de necesidades colectivas en caso de guerra o trastornos interiores; el abastecimiento de las ciudades o centros de población, de víveres o de otros artículos de consumo necesario, y los procedimientos empleados para combatir o impedir la propagación de epidemias, epizootias, incendios, plagas, inundaciones $u$ otras calamidades públicas; VI.- Los medios empleados para la defensa nacional o para el mantenimiento de la paz pública; VII.-

10 Tesis: XXVII.3o.9 A (10a.), Semanario Judicial de la Federación y su Gaceta, Decima Época, t. IV, Noviembre de 2014, p. 2939. 
La defensa, conservación, desarrollo o aprovechamiento de los elementos naturales susceptibles de explotación; VIII.- La equitativa distribución de la riqueza acaparada o monopolizada con ventaja exclusiva de una o varias personas y con perjuicio de la colectividad en general, o de una clase en particular; IX.- La creación, fomento o conservación de una empresa para beneficio de la colectividad; X.- Las medidas necesarias para evitar la destrucción de los elementos naturales y los daños que la propiedad pueda sufrir en perjuicio de la colectividad; XI.- La creación o mejoramiento de centros de población y de sus fuentes propias de vida.

Estas son las causa de utilidad pública por las que el Estado, desde el ámbito federal, puede expropiar sin que constituya una violación al derecho fundamental de la propiedad privada en México, siempre y cuando se cumplan con las formalidades esenciales del procedimiento, se pague la indemnización, además, se cumpla con la causa de utilidad pública, así la reforma viene a proteger el derecho de los particulares sobre sus bienes inmuebles.

\section{LA EXPROPIACIÓN PÚBLICA EN MÉXICO}

La expropiación pública en México debe partir de los principios constitucionales establecidos en el artículo 27 de la CPEUM, es decir, y buscando explicarlos en términos generales para una mejor comprensión de un lector universal, el hecho de que la autoridad o el gobierno le quite, le expropie la propiedad a un dueño particular, tiene que obedecer a dos elementos esenciales, por causa de utilidad pública y mediante indemnización, dicho a contrario sensu, si un particular sufre la situación de que el gobierno (entendido como el Estado ya sea en el ámbito federal o el estatal) le quite su propiedad sin que el acto de autoridad o ese hecho sea por causa de utilidad pública y que lo indemnicen, se estaría ante un acto de autoridad viciado, ilegal, inconstitucional e inconvencional; así lo garantiza el numeral citado, las expropiaciones sólo podrán hacerse por causa de utilidad pública y mediante indemnización, y la capacidad para adquirir el dominio de ellas, se fundamenta en los términos siguientes:

La capacidad para adquirir el dominio de las tierras y aguas de la Nación, se regirá por las siguientes prescripciones

En el párrafo diez del artículo 27 de la CPEUM, se fundamentan las prescripciones supremas por las cuales se rige la forma de adquirir las tierras y aguas en el país, las cuales, por su gran importancia se trascriben a continuación. 
Sólo los mexicanos por nacimiento o por naturalización y las sociedades mexicanas tienen derecho para adquirir el dominio de las tierras, aguas y sus accesiones o para obtener concesiones de explotación de minas o aguas. El Estado podrá conceder el mismo derecho a los extranjeros, siempre que convengan ante la Secretaría de Relaciones en considerarse como nacionales respecto de dichos bienes y en no invocar por lo mismo la protección de sus gobiernos por lo que se refiere a aquéllos; bajo la pena, en caso de faltar al convenio, de perder en beneficio de la Nación, los bienes que hubieren adquirido en virtud del mismo. En una faja de cien kilómetros a lo largo de las fronteras y de cincuenta en las playas, por ningún motivo podrán los extranjeros adquirir el dominio directo sobre tierras y aguas. El Estado de acuerdo con los intereses públicos internos y los principios de reciprocidad, podrá, a juicio de la Secretaría de Relaciones, conceder autorización a los Estados extranjeros para que adquieran, en el lugar permanente de la residencia de los Poderes Federales, la propiedad privada de bienes inmuebles necesarios para el servicio directo de sus embajadas o legaciones.

Las asociaciones religiosas que se constituyan en los términos del artículo 130 de la CPEUM y su ley ${ }^{11}$ reglamentaria tendrán capacidad para adquirir, poseer o administrar, exclusivamente, los bienes que sean indispensables para su objeto;

Las instituciones de beneficencia, pública o privada, que tengan por objeto el auxilio de los necesitados, la investigación científica, la difusión de la enseñanza, la ayuda recíproca de los asociados, o cualquier otro objeto lícito, no podrán adquirir más bienes raíces que los indispensables para su objeto, inmediata o directamente destinados a él;

Las sociedades mercantiles por acciones podrán ser propietarias de terrenos rústicos pero únicamente en la extensión que sea necesaria para el cumplimiento de su objeto. En ningún caso las sociedades de esta clase podrán tener en propiedad tierras dedicadas a actividades agrícolas, ganaderas o forestales en mayor extensión que la respectiva equivalente a veinticinco veces los límites señalados en la fracción XV del artículo 27 de la CPEUM. La ley ${ }^{12}$ reglamentaria regulará la estructura de capital y el número mínimo de socios de estas sociedades, a efecto de que las tierras propiedad de la sociedad no excedan en relación con cada socio los límites de la pequeña propiedad. En este caso, toda propiedad accionaria individual, correspondiente a terrenos rústicos, será acumulable para efectos de cómputo. Asimismo, la ley ${ }^{13}$ señalará las condiciones para la

\footnotetext{
${ }^{11}$ Ley de Asociaciones Religiosas y Culto Público, publicada en el Diario Oficial de la Federación el día 15 de julio del año de 1992, a la cual se le realizó su última reforma el día 17 de diciembre del año 2015 y que prescribe que la Iglesia y asociaciones religiosas pueden usar de forma exclusiva, para fines religiosos, bienes propiedad de la nación, siendo este el origen constitucional de la propiedad privada de esos entes jurídicos.

12 Ley General de Sociedades Mercantiles, publicada en el Diario Oficial de la Federación el día 4 de agosto del año de 1934, a la cual se le realizó su última reforma el día 24 de enero del año 2018 y que prescribe que las sociedades mercantiles pueden usar de forma exclusiva, para el objeto de sus fines, bienes propiedad de la nación, siendo este el origen constitucional de la propiedad privada de esos entes jurídicos.

${ }^{13}$ Ley de Inversión Extranjera, publicada en el Diario Oficial de la Federación el día 27 de diciembre de 1993, a la cual se le realizó su última reforma el día 26 de junio del año 2017, documento que determina
} 
participación extranjera en dichas sociedades. La propia ley establecerá los medios de registro y control necesarios para el cumplimiento de lo dispuesto por esta fracción;

Los bancos debidamente autorizados, conforme a las leyes de instituciones de crédito, podrán tener capitales impuestos, sobre propiedades urbanas y rústicas de acuerdo con las prescripciones de dichas leyes ${ }^{14}$, pero no podrán tener en propiedad o en administración más bienes raíces que los enteramente necesarios para su objeto directo. Las entidades federativas, lo mismo que los Municipios de toda la República, tendrán plena capacidad para adquirir y poseer todos los bienes raíces necesarios para los servicios públicos.

Las leyes de la Federación y de las entidades federativas en sus respectivas jurisdicciones, determinarán los casos en que sea de utilidad pública la ocupación de la propiedad privada, y de acuerdo con dichas leyes la autoridad administrativa hará la declaración correspondiente. El precio que se fijará como indemnización a la cosa expropiada, se basará en la cantidad que como valor fiscal de ella figure en las oficinas catastrales o recaudadoras, ya sea que este valor haya sido manifestado por el propietario o simplemente aceptado por él de un modo tácito por haber pagado sus contribuciones con esta base. El exceso de valor o el demérito que haya tenido la propiedad particular por las mejoras o deterioros ocurridos con posterioridad a la fecha de la asignación del valor fiscal, será lo único que deberá quedar sujeto a juicio pericial y a resolución judicial. Esto mismo se observará cuando se trate de objetos cuyo valor no esté fijado en las oficinas rentísticas.

El ejercicio de las acciones que corresponden a la Nación, por virtud de las disposiciones sobre la expropiación, se hará efectivo por el procedimiento judicial; pero dentro de este procedimiento y por orden de los tribunales correspondientes, que se dictará en el plazo máximo de un mes, las autoridades administrativas procederán desde luego a la ocupación, administración, remate o venta de las tierras o aguas de que se trate y todas sus accesiones, sin que en ningún caso pueda revocarse lo hecho por las mismas autoridades antes que se dicte sentencia ejecutoriada.

Se reconoce la personalidad jurídica de los núcleos de población ejidales y comunales y se protege su propiedad sobre la tierra, tanto para el asentamiento humano como para actividades productivas. La ley protegerá la integridad de las tierras de los grupos indígenas. La ley, considerando el respeto y fortalecimiento de la vida comunitaria de los ejidos y comunidades, protegerá la tierra para el asentamiento humano y regulará el aprovechamiento de tierras, bosques y aguas de uso común y la provisión de acciones de fomento necesarias para elevar el nivel de vida de sus pobladores. La ley, con respeto a la voluntad de los ejidatarios y comuneros para adoptar las condiciones que más les convengan en el

las reglas para la inversión extranjera en México, y en relación a la propiedad privada, su inversión puede ser de hasta el $49 \%$ en sociedades que tengan en propiedad tierras agrícolas, ganaderas y forestales.

${ }^{14}$ Ley de Instituciones de Crédito, publicada en el Diario Oficial de la Federación el día 18 de julio de 1990, a la que se le realizó su última reforma el día 9 de marzo de 2018, documento que regula las operaciones de las instituciones de crédito, entre otras, para celebrar contratos y adquirir los bienes inmuebles necesarios para el cumplimiento de su objeto. 
aprovechamiento de sus recursos productivos, regulará el ejercicio de los derechos de los comuneros sobre la tierra y de cada ejidatario sobre su parcela. Asimismo establecerá los procedimientos por los cuales ejidatarios y comuneros podrán asociarse entre sí, con el Estado o con terceros y otorgar el uso de sus tierras; $y$, tratándose de ejidatarios, transmitir sus derechos parcelarios entre los miembros del núcleo de población; igualmente fijará los requisitos y procedimientos conforme a los cuales la asamblea ejidal otorgará al ejidatario el dominio sobre su parcela. En caso de enajenación de parcelas se respetará el derecho de preferencia que prevea la ley. Dentro de un mismo núcleo de población, ningún ejidatario podrá ser titular de más tierra que la equivalente al $5 \%$ del total de las tierras ejidales. En todo caso, la titularidad de tierras en favor de un solo ejidatario deberá ajustarse a los límites señalados en la fracción XV. La asamblea general es el órgano supremo del núcleo de población ejidal o comunal, con la organización y funciones que la ley señale. El comisariado ejidal o de bienes comunales, electo democráticamente en los términos de la ley, es el órgano de representación del núcleo y el responsable de ejecutar las resoluciones de la asamblea. La restitución de tierras, bosques y aguas a los núcleos de población se hará en los términos de la ley reglamentaria. ${ }^{15}$

Desde la visión de la ciencia jurídica en este punto específico, se analiza el origen de la propiedad de las tierras y aguas en los EUM, siendo que éstas pertenecen originariamente a la Nación, quien tiene la facultad soberana de constituir las diferentes formas de propiedad de ella; así, los mexicanos por nacimiento o por naturalización tienen el derecho de adquirir el dominio de tierras y aguas, también las sociedades mexicanas, de igual forma, los extranjeros con las condicionantes expresadas en el primer párrafo, continuando con el derecho de los países extranjeros de adquirir el inmueble necesario para establecer sus embajadas cumpliendo con el principio de reciprocidad internacional, de igual forma, es el origen de la propiedad ejidal y comunal, ahora bien, todas estas formas de propiedad gozan de los derechos fundamental para protegerlos. Así, el vínculo jurídico entre la propiedad privada y la expropiación, es que resulta indispensable la existencia de la primera para que pueda actualizarse la segunda, es decir, no hay expropiación si no hay propiedad privada.

\section{La causa de utilidad pública y la indemnización}

Las causas de utilidad pública que aprueban la expropiación de la propiedad privada, las publica el Ejecutivo Federal en la Ley de Expropiación en el año de 1936, las cuales ya fueron descritas en el punto 2.3 de esta investigación y las contiene el primer numeral de dicha ley.

\footnotetext{
${ }^{15}$ Véase el artículo 27 de la Constitución Política de los Estados Unidos Mexicanos, publicada el 5 de febrero de 1917, vigente a la fecha.
} 
Al respecto, el Quinto Tribunal Colegiado de Circuito en materia administrativa del Tercer Circuito de la SCJN, sostiene que:

Expropiación. Etapas del procedimiento relativo (legislación vigente en 1974). Para fines prácticos, en sentido amplio, de la Ley de Expropiación vigente en 1974 se advierte que, el trámite de la expropiación consta de las siguientes fases: 1) Trabajos previos que realiza la dependencia solicitante de la expropiación para justificar la causa de utilidad pública ante la secretaría de Estado correspondiente; 2) Formulación de la solicitud de expropiación; 3) Emisión del acuerdo en el que se da respuesta a dicha solicitud; de ser afirmativa, se realiza la declaratoria de causa de utilidad pública de los bienes a expropiar, con lo cual, inicia formalmente el procedimiento de expropiación de que se trata y debe brindarse la garantía de audiencia a los afectados, en términos de la jurisprudencia 2a./J. 124/2006, sustentada por la Segunda Sala de la Suprema Corte de Justicia de la Nación y publicada en el Semanario Judicial de la Federación y su Gaceta, Novena Época, Tomo XXIV, septiembre de 2006, página 278, con el rubro: "EXPROPIACIÓN. LA GARANTÍA DE AUDIENCIA DEBE RESPETARSE EN FORMA PREVIA A LA EMISIÓN DEL DECRETO RELATIVO."; 4) Trabajos técnicos y avalúos del bien a expropiar, entre otros, por parte de la secretaría competente, a cuenta de la dependencia solicitante, a fin de justificar la viabilidad técnica, económica y jurídica de la expropiación; 5) Calificación del expediente de trámite, cuya procedencia conlleva la realización del proyecto de decreto expropiatorio; 6) Emisión del decreto expropiatorio por el titular del Poder Ejecutivo y su publicación en el Diario Oficial de la Federación; y, 7) Ejecución del decreto expropiatorio, como lo es, la posesión u ocupación material del bien, la indemnización y, en su caso, el inicio y la conclusión de las obras a realizarse. ${ }^{16}$

En el ejercicio de la facultad soberana del Estado, para expropiar, tiene la obligación de observar esas dos variables, es decir, debe cumplir con la causa de utilidad pública y la indemnización, pero no solo eso, además, debe de cumplir con la parte adjetiva establecida por la ciencia jurídica, para dar la garantía de audiencia al gobernado expropiado, dicho de otra forma, la facultad soberana del país, para expropiar está sujeta al cumplimiento de la causa de utilidad pública, la indemnización y el debido proceso.

\section{Causa de utilidad pública}

Además, de las causas de utilidad pública desde el ámbito federal, ${ }^{17}$, también, existen en México por cada uno de sus entidades federativas, leyes estatales de expropiación, para el

\footnotetext{
${ }^{16}$ Tesis: III.5o.A.35 A (10a.), Semanario Judicial de la Federación y su Gaceta, Décima Época, t. IV, Enero de 2017, p. 2541.

17 Se consideran causas de utilidad pública: I.- El establecimiento, explotación o conservación de un servicio público; II.- La apertura, ampliación o alineamiento de calles, la construcción de calzadas,
} 
caso del Estado de Baja California se ha contado con la Ley de Expropiación del Estado de Baja

California, publicada en el Periódico Oficial del Estado el 28 de febrero de $1954^{18}$, actualmente,

puentes, caminos y túneles para facilitar el tránsito urbano y suburbano; III.- El embellecimiento, ampliación y saneamiento de las poblaciones y puertos, la construcción de hospitales, escuelas, parques, jardines, campos deportivos o de aterrizaje, construcciones de oficinas para el Gobierno Federal y de cualquier obra destinada a prestar servicios de beneficio colectivo; III Bis. La construcción de obras de infraestructura pública y la prestación de servicios públicos, que requieran de bienes inmuebles y sus mejoras, derivada de concesión, de contrato o de cualquier acto jurídico celebrado en términos de las disposiciones legales aplicables; IV.- La conservación de los lugares de belleza panorámica, de las antigüedades y objetos de arte, de los edificios y monumentos arqueológicos o históricos, y de las cosas que se consideran como características notables de nuestra cultura nacional; V.- La satisfacción de necesidades colectivas en caso de guerra o trastornos interiores; el abastecimiento de las ciudades o centros de población, de víveres o de otros artículos de consumo necesario, y los procedimientos empleados para combatir o impedir la propagación de epidemias, epizootias, incendios, plagas, inundaciones u otras calamidades públicas; VI.- Los medios empleados para la defensa nacional o para el mantenimiento de la paz pública; VII.- La defensa, conservación, desarrollo o aprovechamiento de los elementos naturales susceptibles de explotación; VIII.- La equitativa distribución de la riqueza acaparada o monopolizada con ventaja exclusiva de una o varias personas y con perjuicio de la colectividad en general, o de una clase en particular; IX.- La creación, fomento o conservación de una empresa para beneficio de la colectividad; X.- Las medidas necesarias para evitar la destrucción de los elementos naturales y los daños que la propiedad pueda sufrir en perjuicio de la colectividad; XI.- La creación o mejoramiento de centros de población y de sus fuentes propias de vida; XII.- Los demás casos previstos por leyes especiales.

18 Se consideran causas de utilidad pública: I.- El establecimiento, explotación, conservación o mantenimiento de un servicio público; II.- La apertura, ampliación, prolongación y alineación de calles, la construcción y obras de protección de calzadas, puentes vehiculares o peatonales, caminos, túneles, pasos, vados y sus zonas de mantenimiento, así como la construcción de cualquier obra de infraestructura vial para el mejoramiento de las vías públicas urbanas, suburbanas y rurales de los municipios o del Estado, en beneficio de la colectividad; III.- La constitución de un derecho de vía y áreas necesarias para la construcción o introducción de infraestructura hidráulica, drenaje sanitario, pluviales, gas, electricidad, y cualquier otra red de servicio; V.- La construcción y ampliación de hospitales, dispensarios médicos, centros de recuperación de la salud, asilos, hospicios, guarderías, escuelas para cualquier grado o clase de enseñanza, plazas, parques, jardines, áreas deportivas, auditorios, centros para la difusión de la cultura, área natural protegida, estaciones de transporte, de seguridad pública, centros de readaptación social, panteones, rellenos sanitarios, campos de aterrizaje, edificios para oficina de gobierno, y cualquier obra destinada a prestar servicios de beneficio colectivo. VII.- La conservación de los lugares de belleza panorámica, de las antigüedades y objetos de arte, edificios y monumentos arqueológicos o históricos y de las cosas que se consideren características notables de la cultura nacional, regional o estatal; IX.- Los procedimientos empleados para combatir o impedir la propagación de epidemias, epizootias, incendios, plagas, inundaciones u otro caso fortuito; XI.- La satisfacción de necesidades de reubicación de familias que por motivos de desastres ocasionados por elementos de la naturaleza o atribuibles a la acción humana, pierdan sus hogares o se encuentren en zonas que por el alto riesgo que representan, se inminente la pérdida de vidas humanas; XII.- La regularización de la tenencia de terrenos destinados a vivienda popular y ocupados por grupos sociales de escasos recursos económicos o la reubicación de las mismas por causas de beneficio colectivo o interés social; XIV.- Las medidas necesarias para evitar la destrucción de elementos naturales y los daños que la propiedad pueda sufrir en perjuicio de la colectividad; XVI.- La captación, conducción tratamiento y distribución de agua potable, la construcción y obras de protección de instalaciones para el tratamiento de aguas negras, de canales, drenajes sanitarios, obras de irrigación, desperdicios, pozos, drenajes pluviales, así como de cualquier obra de infraestructura hidráulica que beneficie a la colectividad; XVII.- El aprovechamiento y la transformación de basuras y saneamiento de terrenos; XVIII.- La satisfacción de necesidades colectivas en 
está vigente la Ley de Expropiación para el Estado de Baja California, Publicada en el Periódico Oficial No. 28, de fecha 13 de junio del 2003, Tomo CX ${ }^{19}$.

Al respecto, se puede establecer que la expropiación en el ámbito federal y en el estatal goza de los mismos derechos fundamentales, de lo que el Pleno de la SCJN se ha pronunciado en los siguientes términos:

Expropiación. Es facultad del Congreso de la Unión y de las legislaturas de los estados establecer legalmente las causas de utilidad pública que la

caso de protección, guerra o trastornos interiores, así como el abastecimiento de las ciudades o centros de población, de víveres o de otros artículos de consumo necesario, y los medios empleados para el mantenimiento de la paz y seguridad pública; XX.- La necesidad de víveres, medicinas, y demás objetos indispensables para hacer frente a los casos de riesgo, siniestro o desastre en el caso en que el Estado se encuentre imposibilitado para proveerlos por sus propios medios. XXI.- Los demás casos previstos por las leyes especiales.

19 Se consideran causas de utilidad pública: I.- El establecimiento, explotación, conservación o mantenimiento de un servicio público; II.- La apertura, ampliación, prolongación y alineación de calles, la construcción y obras de protección de calzadas, puentes vehiculares o peatonales, caminos, túneles, pasos, vados y sus zonas de mantenimiento, así como la construcción de cualquier obra de infraestructura vial para el mejoramiento de las vías públicas urbanas, suburbanas y rurales de los municipios o del Estado, en beneficio de la colectividad; III.- La constitución de un derecho de vía y áreas necesarias para la construcción o introducción de infraestructura hidráulica, drenaje sanitario, pluviales, gas, electricidad, y cualquier otra red de servicio; IV.- La restauración o demolición total o parcial de bienes inmuebles en situación de abandono cuando estos generen un riesgo para la seguridad pública, bienes que serán utilizados en beneficio de la colectividad o interés público. V.- La construcción y ampliación de hospitales, dispensarios médicos, centros de recuperación de la salud, asilos, hospicios, guarderías, escuelas para cualquier grado o clase de enseñanza, plazas, parques, jardines, áreas deportivas, auditorios, centros para la difusión de la cultura, área natural protegida, estaciones de transporte, de seguridad pública, centros de readaptación social, panteones, rellenos sanitarios, campos de aterrizaje, edificios para oficina de gobierno, y cualquier obra destinada a prestar servicios de beneficio colectivo. VII.- La conservación de los lugares de belleza panorámica, de las antigüedades y objetos de arte, edificios y monumentos arqueológicos o históricos y de las cosas que se consideren características notables de la cultura nacional, regional o estatal; IX.- Los procedimientos empleados para combatir o impedir la propagación de epidemias, epizootias, incendios, plagas, inundaciones u otro caso fortuito; XI.- La satisfacción de necesidades de reubicación de familias que por motivos de desastres ocasionados por elementos de la naturaleza o atribuibles a la acción humana, pierdan sus hogares o se encuentren en zonas que por el alto riesgo que representan, se inminente la pérdida de vidas humanas; XII.- La regularización de la tenencia de terrenos destinados a vivienda popular y ocupados por grupos sociales de escasos recursos económicos o la reubicación de las mismas por causas de beneficio colectivo o interés social; XIV.- Las medidas necesarias para evitar la destrucción de elementos naturales y los daños que la propiedad pueda sufrir en perjuicio de la colectividad; XVI.- La captación, conducción tratamiento y distribución de agua potable, la construcción y obras de protección de instalaciones para el tratamiento de aguas negras, de canales, drenajes sanitarios, obras de irrigación, desperdicios, pozos, drenajes pluviales, así como de cualquier obra de infraestructura hidráulica que beneficie a la colectividad; XVII.- El aprovechamiento y la transformación de basuras y saneamiento de terrenos; XVIII.La satisfacción de necesidades colectivas en caso de protección, guerra o trastornos interiores, así como el abastecimiento de las ciudades o centros de población, de víveres o de otros artículos de consumo necesario, y los medios empleados para el mantenimiento de la paz y seguridad pública; XX.- La necesidad de víveres, medicinas, y demás objetos indispensables para hacer frente a los casos de riesgo, siniestro o desastre en el caso en que el Estado se encuentre imposibilitado para proveerlos por sus propios medios. XXI.- Los demás casos previstos por las leyes especiales. 
justifiquen. El artículo 27 de la Constitución Política de los Estados Unidos Mexicanos prevé la expropiación de la propiedad privada por causa de utilidad pública y mediante indemnización, así como que corresponde a las leyes de la Federación y de los Estados, en sus respectivos ámbitos competenciales, señalar los casos en que sea de utilidad pública expropiar un bien, correspondiendo a la autoridad administrativa realizar dicha declaración y fijar las reglas generales sobre el precio e indemnización. Esto es, la expropiación constituye un acto de carácter administrativo mediante el cual se priva a los particulares de la propiedad de un bien inmueble, en aras del interés, necesidad o utilidad social, es decir, se trata de una figura a través de la cual el Estado logra determinados fines relacionados con el interés colectivo, de ahí que se sujete la expropiación a causas de utilidad pública. Ahora bien, toda vez que la Constitución Federal no establece un concepto de utilidad pública, el que por abstracto, mutable y relativo es difícil de definir y sólo es determinable por las condiciones políticas, sociales y económicas que imperen en cierta época y lugar, el Constituyente otorgó al Congreso de la Unión y a las Legislaturas Estatales la facultad de establecer, en la ley y dentro de sus respectivos ámbitos de competencia, las causas de esa utilidad pública que, en aras del bien común, sustenten el acto administrativo expropiatorio. ${ }^{20}$

Más allá de que existen las garantías al gobernado de causa de utilidad pública e indemnización, que el Estado debe cumplir, existe una garantía más, el derecho a la reversión, cuando no se cumple con la causa en un plazo de cinco años, por lo que el gobernado puede acudir a la justicia jurisdiccional, para que sea restituido de su propiedad.

Al respecto, los Tribunales Colegiados de Circuito de la SCJN, sostienen que:

Reversión de tierras ejidales. Es a partir de la fecha de publicación del decreto expropiatorio respectivo que comienza a transcurrir el plazo de cinco años para satisfacer la causa de utilidad pública. De los artículos 97 de la Ley Agraria y 94 del Reglamento de la Ley Agraria en Materia de Ordenamiento de la Propiedad Rural se advierte que si transcurrido el plazo de cinco años no se ha cumplido con la causa de utilidad pública, el Fideicomiso Fondo Nacional de Fomento Ejidal ejercitará las acciones necesarias para reclamar la reversión parcial o total, según corresponda, de los bienes expropiados. No obstante ello, esas normas no prevén a partir de qué momento comienza a correr el lapso que contemplan. Para dilucidar tal incógnita, debe atenderse a lo que origina el derecho de reversión o retrocesión, como también lo llama la doctrina, es decir, que no se satisfaga la causa de utilidad pública transcurrido el plazo de cinco años. Así, tomando en cuenta que la norma prevé un plazo especial, no puede ni debe entenderse a éste como un supuesto de vencimiento de la expropiación, sino de la declaratoria de utilidad pública, esto es, de caducidad de la causa de utilidad pública, puesto que si lo que justifica el acto expropiatorio es la existencia de una causa de utilidad pública, entonces es ésta la que también justifica la afectación de la propiedad.

20 Tesis: P./J. 38/2006, Semanario Judicial de la Federación y su Gaceta, Novena Época, t. XXIII, Marzo de 2006, p. 1414. 
Luego, la vigencia de la declaratoria de utilidad pública será la que sustente la vigencia tanto de la declaratoria de expropiación como de la afectación de la propiedad. De esta manera, el referido plazo no es otro que el de la efectividad de la causa de utilidad pública, que inicia desde el momento mismo en que se afecta con motivo de ella a la propiedad. Por ende, si conforme a los artículos 10., fracción II, 3o., fracción VI y 14 de la actualmente abrogada Ley General de Bienes Nacionales, publicada en el Diario Oficial de la Federación el 8 de enero de 1982, aplicable a los asuntos sometidos a su régimen, una vez que se publica el decreto expropiatorio en el señalado medio, los bienes inmuebles salen del patrimonio de su titular (ejido o comunidad) e ingresan a formar parte del dominio privado de la nación, entonces, es desde ese instante en que con motivo de la causa de utilidad pública se afecta a la propiedad y, siendo así, es a partir de la fecha de publicación del decreto expropiatorio respectivo que comienza a transcurrir el plazo de cinco años para satisfacer la causa de utilidad pública. ${ }^{21}$

De lo anterior, podemos enfatizar en que la causa de utilidad pública y la indemnización, son dos elementos constitucionales que aplican en las leyes de la Federación y de los Estados, ambos en sus respectivos ámbitos competenciales, pero aun habiéndose actualizado esos supuestos, si el Estado expropiante no concretiza la causa de utilidad pública, es decir, no construye, no lotifica, incumple el objeto de realización para la satisfacción de la causa de la necesidad pública, el propietario originario cuenta con el recurso de reversión, para que vuelva el bien a su patrimonio, es decir, que vuelva a ser propiedad privada.

\section{Indemnización}

Se sostiene que la indemnización, en el caso de la expropiación, es el monto en numerario o en especie que el particular expropiado tiene derecho a recibir por el daño causado en su esfera patrimonial por la privación de sus bienes, sostiene que se fija con base del tipo de bien de que se trate, es decir, si es bien inmueble o bien mueble, si es el primero, bien inmueble, el monto de la indemnización será el valor comercial del bien obtenido de un avalúo practicado por persona autorizada, sin que dicho monto sea inferior al valor catastral; si es mueble, el monto de la indemnización será el valor comercial del bien obtenido de un avaluó practicado por persona autorizada (GONZÁLEZ, 2015).

Al respecto, el Quinto Tribunal Colegiado de Circuito del Tercer Circuito de la SCJN, sostiene que:

\footnotetext{
${ }^{21}$ Tesis: XXVII.1o. (VIII Región) 2 A (10a.), Semanario Judicial de la Federación y su Gaceta, Décima Época, t. 2, Marzo de 2012, p. 1394.
} 
Expropiación. A la indemnización por este concepto son inaplicables supletoriamente las reglas de la prescripción, previstas en el Código Civil para el Distrito Federal (actualmente ciudad de México) (legislación vigente en 1974). Conforme a los artículos 27, segundo párrafo, de la Constitución Política de los Estados Unidos Mexicanos y 21, numeral 2, de la Convención Americana sobre Derechos Humanos, las expropiaciones sólo podrán hacerse por causa de utilidad pública y mediante indemnización. Por su parte, de la Ley de Expropiación vigente en 1974 se advierte que, para el reclamo del importe y/o tramitación de la indemnización por concepto de expropiación, el legislador no estableció medio de defensa alguno cuya falta de interposición diera lugar a declarar su firmeza, ni estatuyó la figura jurídica de la prescripción, sino únicamente señaló en el artículo 20 que la autoridad expropiante fijará la forma y los plazos en que debía resarcirse al afectado, los que nunca abarcarían un periodo mayor a diez años, en aras de generar seguridad jurídica al afectado sobre el periodo con que cuenta la autoridad expropiante para resarcirlo. En estas condiciones, si bien es cierto que los numerales 10 y 11 de la ley citada aluden a una controversia en materia de indemnización en la que interviene un Juez civil y se tramita el procedimiento respectivo en términos del Código Civil para el Distrito Federal (actualmente Ciudad de México), también lo es que ésta únicamente se constriñe a decidir la estimación del valor de las mejoras o deterioros ocurridos al bien con posterioridad a la fecha de la asignación del valor fiscal, lo que significa que, salvo ese caso, la legislación de derecho privado señalada no aplica supletoriamente al procedimiento de expropiación. Por tanto, a la indemnización por expropiación, son inaplicables supletoriamente las reglas de la prescripción, previstas en el código referido. Estimar lo contrario, constituiría una figura jurídica no establecida en el cuerpo normativo especial correspondiente, aparte de que de su contenido no se obtiene que el legislador tuviera la intención de incorporarla. 22

Habiendo establecido que es la indemnización por expropiación y que su pago en numerario será a valor comercial mediante avaluó, es importante esclarecer que no le son aplicables supletoriamente las reglas de la prescripción, por lo que no se puede adquirir la propiedad de un inmueble expropiado por prescripción, si no solo la indemnización si al momento de decretarse aquella se acredita la propiedad del inmueble.

Continuando con el análisis en relación a la indemnización por expropiación la Segunda Sala de la SCJN, sostiene que:

Indemnización por concepto de expropiación. Sólo corresponde al propietario del bien inmueble. El derecho a la propiedad privada reconocido por los artículos 14, 16 y 27 de la Constitución Política de los Estados Unidos Mexicanos puede ser afectado para atender a una función social en aras del interés colectivo, empero, el propio parámetro de regularidad constitucional contiene prescripciones que permiten que

\footnotetext{
22 Tesis: III.5o.A.34 A (10a.), Semanario Judicial de la Federación y su Gaceta, Décima Época, t. IV, Enero de 2017, p. 2540.
} 
el "propietario" cuente con garantías necesarias para que no disminuya su patrimonio de manera arbitraria, como lo es que en los casos de expropiación por causa de utilidad pública se le otorgue una justa indemnización. En ese sentido, el diseño constitucional se dirige a compensar a quien cuenta con el título de propiedad del bien respectivo, en la inteligencia de que es a quien efectivamente se le priva del bien inmueble que forma parte de su patrimonio, generándose con ello la correlativa afectación a su derecho fundamental a la propiedad privada, no así a quien únicamente cuenta con la posesión, pues en todo caso, éste sólo tiene una expectativa jurídica de obtener el derecho de dominio sobre ese bien, previo cumplimiento de los requisitos legales -mediante la figura de la prescripción adquisitiva- $y$, por ende, es inconcuso que no habiendo obtenido aún la propiedad -ni pasado ésta a su patrimonio-, no habría lugar a que se le otorgaran las prerrogativas inherentes que acompañan a tal título, como lo es que el Estado Mexicano le otorgue una justa indemnización en caso de expropiación. En suma, tratándose de la indemnización con motivo de una expropiación, no es dable equiparar la figura de la posesión con la diversa de propiedad. ${ }^{23}$

Afirmando que la indemnización por expropiación, comparado con la expectativa del derecho de la prescripción positiva en la que no aplica la indemnización en esta figura jurídica, pues solo aplica al propietario, quien tiene título o escritura pública que demuestre legalmente ser el propietario del inmueble de que se trate y que la indemnización será en base a avaluó a valor comercial. Bajo estas premisas, se aborda el tema de la expropiación privada por causa de utilidad pública en el Estado de Baja California, México.

\section{LA EXPROPIACIÓN PÚBLICA EN BAJA CALIFORNIA}

Para abordar la variable de estudio de las entidades federativas en los EUM en relación al objeto de estudio, se utilizó como referente lo establecido en las normas jurídicas respecto al Estado de Baja California, partiendo de los antecedentes de reformas en el ámbito federal, para después delimitarlos al ámbito estatal, de ésta forma se continua al respecto:

Marat y José María, establecen concretizando que: la Ley de Expropiación proviene de 1936, desde entonces ha sufrido muy pocas modificaciones. En diciembre de 1949 se adicionó para que mencionara que la construcción de oficinas para el gobierno federal era causa de utilidad pública. En diciembre de 1993, con el NAFTA al entrar en vigor, se hicieron algunas modificaciones: a) se precisó un plazo de 45 días para que la autoridad resolviera sobre la reversión del bien; b) se le denominó decreto al ordenamiento por el que se dispone la expropiación, y c) también se indicó que el precio que se fijara como indemnización debería ser equivalente a su valor comercial, que debía pagarse en moneda y no

\footnotetext{
23 Tesis: 2a. LVI/2017 (10a.), Semanario Judicial de la Federación y su Gaceta, Décima Época, t. I, Abril de 2017, p. 1069.
} 
en especie, reduciendo el plazo para el pago de diez a un año. En diciembre de 1997, en el contexto de los cambios legislativos que precedieron a la reforma constitucional sobre el Distrito Federal (ahora ciudad de México), se dispuso la facultad del Jefe de Gobierno del Distrito Federal de declarar la expropiación. (PAREDES y SOBERANES, 2009)

De lo anterior, comentado por los autores, se deduce que se trata de la obligación jurisprudencial de que rija la audiencia previa en los casos de expropiación, porque es jurisprudencia firme de la Segunda Sala que dicha garantía debe otorgarse de manera previa en los procedimientos de expropiación.

Al respecto, los Tribunales Colegiados de Circuito de la SCJN, sostienen que:

Posesión. No se interrumpe con la sola publicación del decreto expropiatorio (Legislación del Estado de Baja California). El artículo 819, fracción VII, del Código Civil del Estado de Baja California establece que la posesión se pierde por expropiación por causa de utilidad pública. El término "expropiación" debe interpretarse en su acepción jurídica, esto es, como el acto administrativo en virtud del cual el Estado, para el cumplimiento de un fin de utilidad pública, priva de un bien a su titular, siguiendo un determinado procedimiento y pagando una indemnización; sus elementos son: a) la causa de utilidad pública (elemento final); b) el bien expropiable (elemento objetivo); c) el expropiante y el expropiado (elemento subjetivo); d) la indemnización (elemento material), y e) el procedimiento y plazo (elemento formal). Ahora bien, conforme a la Ley de Expropiación del Estado, vigente hasta el trece de junio de 2003, el procedimiento de expropiación inicia con la declaratoria de utilidad pública y concluye con la ocupación del inmueble (pasando por la publicación del acuerdo expropiatorio), de ahí que no es suficiente para considerar que se interrumpió la posesión del bien expropiado, la sola publicación del decreto correspondiente, si no se acredita en juicio que se culminó con el procedimiento de expropiación, ya que, como se anticipó, la expropiación está constituida por todo el procedimiento previsto en la ley y no sólo por la publicación del decreto relativo. ${ }^{24}$

Actualmente, en el Estado de Baja California México, rige la Ley de Expropiación para el

Estado de Baja California, publicada en el Periódico Oficial No. 28, de fecha 13 de junio del 2003, en el tomo CX, la cual establece que la propiedad privada en el Estado podrá ser expropiada, por causa de utilidad pública y mediante indemnización; siendo objeto de expropiación los bienes muebles o inmuebles ${ }^{25}$, para ésta y todas las entidades federativas de los

\footnotetext{
24 Tesis: XV.4o.1 A, Semanario Judicial de la Federación y su Gaceta, Novena Época, t. XX, Noviembre de 2004, p. 2001.

25 Dice que los efectos de la expropiación serán: I.- Los bienes apropiados pasarán al patrimonio del beneficiario, libres de gravamen, sin necesidad de formalidad alguna; II.- Los bienes expropiados serán inalienables e imprescriptibles, en tanto no se verifiquen las finalidades de utilidad pública que hayan motivado la expropiación; III.- En caso de bienes inmuebles, deberá ordenarse en su caso la extinción de las hipotecas que existan sobre los mismos, de conformidad con lo dispuesto por el Código Civil para el Estado de Baja California; IV.- Los contratos de arrendamiento o de cualquier otra clase, por los que se
} 
EUM, son aplicables los principios, derechos fundamentales y garantías constitucionales o mecanismos de control constitucional que se analizan en esta investigación, por ello, se dan aquí por reproducidas.

Sin embargo, siendo el objeto de estudio la norma jurídica que rige la expropiación, es decir, el objeto de estudio en esta investigación, es la expropiación pública en Baja California, una violación al derecho fundamental de la propiedad privada en México, se afirma que las tierras y aguas pertenecen originariamente al concepto de nación, ésta tiene la facultad soberana, aunque no arbitraria, de instituir la propiedad privada, ésta es un derecho fundamental que goza de los mecanismos de control constitucional, por tanto, si la expropiación en esa entidad federativa se realiza contradiciendo alguno de los principios constitucionales, constituye una violación al derecho fundamental a la propiedad privada, en caso contrario, si se cumple y se respeta con todo el sistema jurídico que rige a la expropiación, es una facultad soberana que no viola derechos fundamentales, por el contrario, protege el interés colectivo de la nación.

Habiendo reflexionado sobre la propiedad privada en México y su expropiación por parte del Estado mexicano, se debe enfatizar en que, si bien es cierto, es una facultad soberana la expropiación, también lo es, que ese acto de autoridad no debe ser arbitrario, por lo que, para el caso de que así sea, existen los mecanismos de control constitucional, para que esta se respete, para el caso en estudio son el juicio de amparo indirecto o biinstancial o el juicio de amparo directo o uniistancial.

\section{EL MECANISMO DE CONTROL CONSTITUCIONAL ANTE LA VIOLACIÓN A ESE DERECHO HUMANO}

El mecanismo de control constitucional ante la violación del derecho humano a la propiedad privada en México, se encuentra instituido en la CPEUM, pues el Estado mexicano reconoce la pertenencia privada al estar consagrada en la parte dogmática de su Constitución y, está protegido por el sistema jurídico de forma sistémica, es decir, que para llegar al mecanismo de control constitucional, que es el juicio de amparo, se tendrán que agotar todas las instancias, primero la etapa administrativa, después la etapa jurisdiccional ante el Tribunal de lo Contencioso Administrativo y al final si la sentencia es adversa, procederá el juicio de amparo

haya transmitido a terceros la posesión derivada, el uso o el aprovechamiento de inmuebles expropiados, quedarán extinguidos.

Revista de Direito da Cidade, vol. 10, no 3. ISSN 2317-7721 pp. 1868-1894 
directo, por tanto, se debe de agotar el principio de definitividad, debiendo el Estado garantizar la audiencia previa y el debido proceso.

La audiencia previa no es más que un procedimiento, un requisito para su limitación por el poder público. La expropiación es otro de los procedimientos constitucionales con los que se puede limitar la propiedad. En ese sentido, la cuestión a debate no es si se puede expropiar menoscabando derechos fundamentales, sino si el procedimientos constitucional de expropiación incluye la formalidad a la que alude el 14 constitucional, (PAREDES y SOBERANES, 2009).

Al respecto la Primera Sala de la SCJN, sostiene que la afectación a la propiedad privada, por parte del Estado, es constitucionalmente posible al reconocerse la figura de la expropiación:

Expropiación. La causa de utilidad pública y la indemnización relativa son garantías de protección del derecho de propiedad (interpretación de los artículos 27, párrafo segundo de la Constitución Federal y 21.2 de la Convención Americana sobre Derechos Humanos). El artículo 27, segundo párrafo, de la Constitución Política de los Estados Unidos Mexicanos determina que las expropiaciones sólo podrán hacerse por causa de utilidad pública y mediante indemnización. Por su parte, el artículo 21.2 de la Convención Americana sobre Derechos Humanos establece que ninguna persona puede ser privada de sus bienes, excepto mediante el pago de una indemnización justa, por razones de utilidad pública o de interés social y en los casos y según las formas establecidas por la ley. En dichos términos, la afectación a la propiedad privada, por parte del Estado, es constitucionalmente posible al reconocerse la figura de la expropiación. No obstante, dicho acto implica la afectación del derecho de propiedad, el cual no puede ser arbitrario porque, en el caso contrario, el derecho de propiedad no tendría vigencia real. Es decir, el titular de la propiedad no puede considerar protegido su bien si el Estado tuviera la posibilidad de afectarlo sin estar sujeto a restricciones que autoricen su actuación. Por ello, si la propiedad privada se encuentra protegida frente al interés de expropiación por parte del Estado, se debe a que la actuación de este último está sujeta a dos elementos que le exigen ejercer la afectación sólo cuando existe justificación y se realice una reparación al titular de la propiedad privada. Es decir, la causa de utilidad pública y la indemnización no son derechos humanos sino garantías de protección del derecho humano a la propiedad privada, frente al interés de expropiación por parte del Estado. ${ }^{26}$

La propiedad privada es un derecho humano en México, la causa de utilidad pública y la indemnización son garantías de protección de ese derecho, cuando uno o dos de esos seguros no los cumple el expropiante, nace la legitimación del expropiado para ejercer el mecanismos de control constitucional ante esa violación, el cual es el juicio de amparo indirecto o el directo,

\footnotetext{
${ }^{26}$ Tesis: 1a. CCLXXXVIII/2014 (10a.), Semanario Judicial de la Federación y su Gaceta, Décima Época, t. I, Agosto de 2014, p. 529.
} 
para esto, se debe agotar el principio de definitividad, es decir, observando los medios de defensa ordinarios establecidos desde el procedimiento administrativo.

En el procedimiento administrativo que debe idear el legislador deben cumplirse, desde luego, con las previsiones constitucionales. En este sentido, siempre se debe regular un procedimiento de defensa de los afectados por la expropiación. Se trata de una exigencia derivada del principio de Estado de Derecho y del derecho a la tutela judicial efectiva. Sin embargo, la posibilidad de defensa puede ser anterior o posterior. (PAREDES Y SOBERANES, 2009)

Al respecto, los Tribunales Colegiados de Circuito de la SCJN, sostienen que la garantía de audiencia rige después de dictado el decreto expropiatorio, pero acepta cuestionar todo el procedimiento:

Expropiación. La garantía de audiencia rige después de dictado el decreto y permite cuestionar todo el procedimiento relativo. De lo dispuesto en la Ley de Expropiación se desprende que el acto administrativo expropiatorio consta de dos etapas. La primera, comprendida entre el inicio del procedimiento en que se declara la causa de utilidad pública y la emisión del decreto correspondiente, en la que el Estado debe realizar, de manera unilateral, estudios para fundar y motivar la causa de utilidad pública y la necesidad de la obra a la cual va a destinar los bienes expropiados. La segunda, que abarca desde la notificación del decreto a los interesados hasta que se lleva a cabo su total ejecución. De acuerdo con la naturaleza de cada una de esas fases, en la primera no es exigible otorgar audiencia a los interesados, pues este requisito no está comprendido en el artículo 27 constitucional, salvo que en la ley se hubiese fijado en la normatividad aplicable un procedimiento con audiencia previa del interesado, en cuyo caso sería necesario agotar ese procedimiento. En cambio, en la segunda etapa sí rige la garantía de audiencia, pues debe notificarse el decreto al interesado para que pueda desplegar su defensa en alguna de las siguientes vías: interponer el recurso de revocación contra ese decreto; cuestionar judicialmente el monto de la indemnización que se haya fijado por el bien materia de la expropiación; exigir el pago de la indemnización una vez vencido el plazo legal; en su caso, solicitar la reversión de la expropiación cuando dentro del plazo legal no se destine la cosa al fin público que se invocó en el decreto; o incluso promover directamente el juicio de amparo en contra del decreto y los vicios de que pudiere adolecer el procedimiento expropiatorio, en los casos en que se actualice alguna excepción al principio de definitividad. ${ }^{27}$

Es importante hacer énfasis en el mecanismo de control constitucional ante la violación al derecho humano de la propiedad privada en México, deducido de la tesis jurisprudencial que nos precede, y se integra con los mecanismos siguientes: el recurso de revocación contra el decreto; cuestionar judicialmente el monto de la indemnización que se haya fijado por el bien

\footnotetext{
${ }^{27}$ Tesis: I.15o.A.3 A, Semanario Judicial de la Federación y su Gaceta, Novena Época, t. XX, Diciembre de 2004, p. 1344.
} 
materia de la expropiación; exigir el pago de la indemnización una vez vencido el plazo legal; en su caso, solicitar la reversión de la expropiación cuando dentro del plazo legal no se destine la cosa al fin público que se invocó en el decreto; o promover directamente el juicio de amparo en contra del decreto y los vicios de que pudiere adolecer el procedimiento expropiatorio, finalmente se cuenta con el recurso de reversión.

Al respecto, la Segunda Sala de la SCJN, sostiene que se cuenta con un plazo de dos años para ejercer la acción del recurso de reversión:

Reversión de bienes ejidales o comunales expropiados. Prescripción de la acción relativa. Si bien es cierto que los artículos 93 y 97 de la Ley Agraria, publicada en el Diario Oficial de la Federación el veintiséis de febrero de mil novecientos noventa y dos, establecen, respectivamente, que los bienes ejidales 0 comunales pueden ser expropiados por alguna causa de utilidad pública mediante decreto presidencial y que cuando aquéllos se destinen a un fin distinto del señalado en el decreto respectivo, o si transcurrido un plazo de cinco años no se ha cumplido con la causa de utilidad pública, el fideicomiso Fondo Nacional de Fomento Ejidal podrá ejercer las acciones necesarias para reclamar la reversión parcial o total de dichos bienes y para que opere la incorporación de éstos a su patrimonio, también lo es que ni en dicha ley ni en el Código Civil Federal, de aplicación supletoria a ésta, se prevé la prescripción de la acción de reversión, por lo que al respecto resulta aplicable la Ley General de Bienes Nacionales, que en su artículo 33, párrafo segundo, dispone que los propietarios que tengan derecho a demandar la reversión de los bienes expropiados, tendrán un plazo de dos años para ejercer sus derechos, contados a partir de la fecha en que aquélla sea exigible. Lo anterior es así, porque conforme a lo dispuesto en el artículo 3o., fracción $\mathrm{VI}$, de la ley últimamente citada, una vez que surte sus efectos el decreto expropiatorio, el bien inmueble sale del patrimonio del ejido e ingresa a los bienes del dominio privado de la Federación. ${ }^{28}$

El recurso de reversión, para el supuesto de que no se cumpla en el plazo establecido la causa de utilidad pública, si bien es un recurso en la etapa administrativa, se considera un mecanismo de control constitucional porque ante el eventual incumplimiento de la causa, el bien expropiado puede volver a su propietario particular, teniendo el derecho a ejercer el juicio de amparo en la tramitación de ese recurso ante la eventual negativa de la autoridad en el ejercicio de la acción de la reversión.

\footnotetext{
${ }^{28}$ Tesis: 2a./J. 26/2001, Semanario Judicial de la Federación y su Gaceta, Novena Época, t. XIV, Julio de 2001, p. 501.
} 


\section{CONCLUSIÓN}

El origen de la propiedad de la tierra y el agua en los EUM se encuentra en el concepto de nación, ésta tiene la facultad soberana para la trasmisión de su dominio constituyendo la propiedad privada, esta es el derecho real más amplio para usar, gozar y disponer de las cosas, dentro del sistema jurídico positivo de limitaciones y modalidades impuestas por el legislador de cada época, la propiedad privada en México es un derecho fundamental, los derechos fundamentales son aquellos derechos humanos reconocidos y positividades en la ley suprema de una nación, para el caso de los EUM, son derechos fundamentales aquellos derechos humanos reconocidos y establecidos en la CPEUM.

María Candelaria, resume que el ideario de los derechos humanos, se presenta como el fundamento de las doctrinas axiológicas que posicionan al sujeto como epicentro de los atributos que le resultan inherentes a su propia naturaleza. En este sentido, la dignidad y los caracteres inmanentemente propios a la naturaleza del hombre, cobran todo su sentido en el fundamento de su reconocimiento. El derecho a la libertad constituye base fundamental de la esfera humana. (Del Pino Padrón, 2017)

Uno de los principios que rigen a los derechos humanos es el de progresividad ${ }^{29}$, lo que se puede explicar en esta investigación, al observar el avance a partir de que en la facultad de expropiación no era aplicable la garantía de audiencia, lo que avanza y ahora se obliga constitucional y legalmente al Estado mexicano a cumplir con esa garantía, pues en el caso contrario su acto es arbitrario, viciado, ilegal, inconstitucional y, por tanto, es revocable.

La expropiación pública en México debe partir de los principios constitucionales establecidos en el artículo 27 de la CPEUM, es decir, el hecho de que la autoridad o el gobierno le quite, le expropie la propiedad a un particular, tiene que obedecer a dos elementos esenciales, por causa de utilidad pública y mediante indemnización, dicho a contrario sensu, si un particular sufre la situación de que el gobierno le quite su propiedad sin que el acto de autoridad o ese hecho sea por causa de utilidad pública y que lo indemnicen, encuadraría en el supuesto jurídico de ser un acto arbitrario, viciado, ilegal, inconstitucional, ante lo que procedería ejercer los mecanismos de control constitucional.

En una expropiación en sentido estricto no se priva a un particular de un derecho, no se le confisca, sino que se le intercambia por su valor. Lo que la autoridad debe probar es que hay una causa de interés público, para

\footnotetext{
${ }^{29}$ Se considera que el principio de progresividad, se explica en el desarrollo de la presente investigación, partiendo del constructivismo, en cuanto al dominio del conocimiento previo de los principios que rigen a los derechos humanos, entre ellos el de progresividad.
} 
imponer su decisión, pero se debe pagar el precio de mercado, el existente antes de las acciones de gobierno (MAYER-SERRA y PÉREZ DE ACHA, 2009).

En el Estado de Baja California México, rige la Ley de Expropiación para el Estado de Baja California, publicada en el Periódico Oficial No. 28, de fecha 13 de junio del 2003, en el tomo CX, la cual establece que la propiedad privada en el Estado podrá ser expropiada, por causa de utilidad pública y mediante indemnización; siendo objeto de expropiación los bienes muebles o inmuebles; se utilizó como referente en el estudio esta entidad federativa, porque los resultados son replicables a todos los Estados de México, porque para esa y todas las entidades federativas, son aplicables los principios, derechos fundamentales y mecanismos de control constitucional que se analizan en la investigación.

Siendo el objeto de estudio la norma jurídica que rige la expropiación, es decir, el objeto de estudio en esta investigación es la expropiación pública en Baja California, una violación al derecho fundamental de la propiedad privada en México, se afirma que las tierras y aguas pertenecen originariamente al concepto de nación, esta tiene la facultad soberana, aunque no arbitraria, de instituir la propiedad privada, esta es un derecho fundamental que goza de los mecanismos de control constitucional, por tanto, si la expropiación en esa entidad federativa se realiza contradiciendo alguno de los principios constitucionales, constituye una violación al derecho fundamental de la propiedad privada, en caso contrario, si se cumple y se respeta con todo el sistema jurídico que rige a la expropiación, se está ante una facultad soberana que no viola derechos fundamentales, por el contrario, protege el interés colectivo de la nación.

Carlos Elizondo y Luis Manuel afirman que: La expropiación fue uno de los instrumentos centrales de los gobiernos postrevolucionarios. Se efectuaron diversos abusos sobre todo porque no le era aplicable la garantía de audiencia previa establecida en el artículo $14^{30}$ constitucional. Sin este criterio no hubiera sido posible la nacionalización del petróleo ni la bancaria. No obstante, a principios de 2006 la SCJN emitió un criterio con el cual toda expropiación debe conferir obligatoriamente a los propietarios el derecho de audiencia previa. (MAYER-SERRA y PÉREZ DE ACHA, 2009)

El mecanismo de control constitucional ante la violación al derecho fundamental de la propiedad privada en Baja California México, es sistémico, porque se integra desde la fase administrativa, la jurisdiccional y la constitucional, con los medios o recursos establecidos: el

\footnotetext{
30 Nadie podrá ser privado de la libertad o de sus propiedades, posesiones o derechos, sino mediante juicio seguido ante los tribunales previamente establecidos, en el que se cumplan las formalidades esenciales del procedimiento y conforme a las Leyes expedidas con anterioridad al hecho. Este mandamiento constitucional es lo que fundamenta la garantía de audiencia previa, la cual consiste en que debe ser oído y vencido en juicio todo gobernado antes de privarlo de cualquier derecho, entre ellos, la propiedad privada.
} 
recurso de revocación contra el decreto expropiatorio; cuestionar judicialmente el monto de la indemnización que se haya fijado por el bien materia de la expropiación; exigir el pago de la indemnización una vez vencido el plazo legal; en su caso, solicitar la reversión de la expropiación cuando dentro del plazo legal no se destine la cosa al fin público que se invocó en el decreto; o promover directamente el juicio de amparo en contra del decreto y los vicios de que pudiere adolecer el procedimiento expropiatorio, finalmente, se cuenta con el recurso de reversión. Por lo que se afirma que se tiene el derecho de ejercitar la acción de amparo, durante todo el proceso de expropiación, sosteniendo entonces, que tanto los recursos administrativos, como los jurisdiccionales y los constitucionales, integran el sistema del mecanismo de control constitucional ante la violación al derecho humano de la propiedad privada en México.

Considerando, que la autoridad debería expropiar ante una causa de utilidad pública que se demuestra con prueba plena indubitable y, que se debe actualizar la indemnización al tiempo del pago, al no ser así, se cree que en México, se viola el derecho fundamental a la propiedad privada, ante la cual, el gobernado goza de todo un sistema jurídico de protección con el cual puede revertir el acto de autoridad arbitrario.

\section{REFERENCIAS BIBLIOGRÁFICAS}

CONSTITUCIÓN POLÍTICA DE LOS ESTADOS UNIDOS MEXICANOS, publicada en el Diario Oficial de la Federación el 5 de febrero de 1917.

DEL PINO PADRÓN, María C. LA VULNERACIÓN DE LOS DERECHOS EN EL FENÓMENO DE LA TRATA. Revista de Direito da Cidade, Brasil, vol. 09, no. 4, p. 1475, DOI: 10.12957/rdc.2017.29151.

GONZÁLEZ, Luis Gerardo. LA EXPROPIACIÓN DE BIENES INMUEBLES EN MÉXICO Implicaciones tributarias para el particular expropiado: México, 1a Ed., Editorial TIRANT LO BLANCH, 2015.

http://sjf.scjn.gob.mx/sjfsist/Paginas/ResultadosV2.aspx?Epoca=1e3e10000000000\&Apendice= 1000000000000\&Expresion=causa\%20de\%20utilidad\%20publica\&Dominio=Rubro,Texto\&TATJ= $2 \&$ Orden $=1 \&$ Clase $=$ TesisB $\&$ \&c $=J$ urisprudencia. Resultados\&TesisPrincipal=TesisPrincipal\&Instan ciasSeleccionadas=6,1,2,50,7\&Hits=20, consultado el 09 de marzo de 2017.

http://sjf.scjn.gob.mx/sjfsist/Paginas/ResultadosV2.aspx?Epoca=1e3e10000000000\&Apendice= 1000000000000\& Expresion=mediante\%20indemnizacion\&Dominio=Rubro,Texto\&TATJ=2\&Ord en $=1 \&$ Clase $=$ TesisB $\&$ bc=Jurisprudencia. Resultados\&TesisPrincipal=TesisPrincipal\&InstanciasSel eccionadas=6,1,2,50,7\&Hits=20, consultado el 09 de marzo de 2017.

http://sjf.scjn.gob.mx/sjfsist/Documentos/Tesis/329/329819.pdf, consultado el 25 de marzo de 2017. 
Ley de Expropiación, publicada en el Diario Oficial de la Federación el 25 de noviembre de 1936.

Ley de Expropiación del Estado de Baja California, publicada en el Periódico Oficial del Estado el 28 de febrero de 1954.

Ley de Expropiación para el Estado de Baja California, Publicada en el Periódico Oficial No. 28, de fecha 13 de junio del 2003, Tomo CX.

MAYER-SERRA, Carlos E., y PÉREZ DE ACHA, Luis M. ¿UN NUEVO DERECHO O EL DEBILITAMIENTO DEL ESTADO? GARANTÍA DE AUDIENCIA PREVIA EN LA EXPROPIACIÓN. Cuestiones Constitucionales Revista Mexicana de Derecho Constitucional, México, n.21, p. 99, jul. / Diciembre. 2009.

PAREDES, Marat, y SOBERANES, José M. LAS REFORMAS A LA LEY DE EXPROPIACIÓN RELACIONADAS CON LA GARANTÍA DE AUDIENCIA PREVIA. Cuestiones Constitucionales Revista Mexicana de Derecho Constitucional, México, n.21, p. 493, jul. / Diciembre. 2009.

Trabalho enviado em 02 de abril de 2018.

Aceito em 26 de junho de 2018. 